\title{
Synthesis, Morphology and Magnetic Characterization of Zn Ferrite Powders
}

\author{
S. A. Popescu ${ }^{1}$, P. Vlazan ${ }^{1}$, P. V. Notingher ${ }^{2}$, S. Novaconi ${ }^{1}$, I. Grozescu ${ }^{1}$, A. Bucur ${ }^{1}$, P. Sfirloaga ${ }^{1}$ \\ ${ }^{1}$ National Institute for Research and Development in Electrochemistry and Condensed Matter, Timisoara, Romania; ${ }^{2}$ Politehnica \\ University of Bucharest, Electrical Engineering Faculty, Bucharest, Romania. \\ Email: simona2008@gmail.com
}

Received September $3^{\text {rd }}, 2010$; revised September $27^{\text {th }}, 2010$; accepted October $3^{\text {rd }}, 2010$.

\begin{abstract}
We synthesized $\mathrm{Zn}_{0.8} \mathrm{Fe}_{2.2} \mathrm{O}_{4}$ ferrite powders by coprecipitation and hydrothermal techniques and analyzed the morphology and magnetic properties. The morphology and structure of the Zn ferrite powders were investigated using Scanning Electron Microscopy (SEM) and X-ray Diffraction (XRD) identifying the crystallization planes. Magnetic hysteresis curves were obtained for the Zn ferrites samples.
\end{abstract}

Keywords: Zn Ferrites, Hysteresis, Morphology and Structure

\section{Introduction}

Ferrite nanopowders have scientific and technological importance in recent years due to their magnetic properties and have a broad range of applications such as magnetic recording, ferrofluids, magnetic resonance imaging, biomedicine, catalyst, etc. [1,2]. They have been used for high-frequency transformers cores, rod antennas, radio frequency coils and more recently as radar-absorbing materials $[3,4]$. Spinel ferrites are materials with good magnetic and electronic properties, which depend strongly on the cation distribution among the tetrahedral and octahedral sites [5]. Ferrite materials can also absorb electromagnetic radiation in the microwave bands when cast in various forms, e.g., sheets, paints, films, ceramic tiles, powders, and loads in matrix composites or mixed with a conducting material [6-11]. Among the spinel ferrites, $\mathrm{Zn}$ ferrites are utilized as electromagnetic wave absorbing materials $[12,13]$.

In this work we analyzed the morphological and magnetic properties of $\mathrm{Zn}_{0.8} \mathrm{Fe}_{2.2} \mathrm{O}_{4}$ powders synthesized by the coprecipitation and hydrothermal techniques.

\section{Experimental Procedure}

The $\mathrm{Zn}_{0.8} \mathrm{Fe}_{2.2} \mathrm{O}_{4}$ ferrite powders were prepared by coprecipitation (sample S1 in Figure 1(a)) and hydrothermal technique (sample S2 in Figure 1(b)) using iron nitrate, zinc nitrate and sodium hydroxide as reaction agents.

To obtain $\mathrm{Zn}_{0.8} \mathrm{Fe}_{2.2} \mathrm{O}_{4}$ ferrite powders using the coprecipitation method we have mixed iron nitrate, zinc nitrate and sodium hydroxide with bidistilled water. The solution was heated to $90^{\circ} \mathrm{C}$ during 5 hours on a Magnetic Agitator at $400 \mathrm{rpm}$. To obtain the final zinc ferrite powder the solution was then cleaned with bidistilled water and alchool, filtered for 5 hours for neutral $\mathrm{pH}$ and calcinated in a Nabertherm Oven at $200^{\circ} \mathrm{C}$ for 2 hours.

Using the hydrothermal method for synthesing zinc ferrite we combined iron nitrate and zinc nitrate with bidistilled water and sodium hydroxide and introduced it in an autoclave for 5 hours at $200^{\circ} \mathrm{C}$ in an Heraeus 6060 UT Stove. To obtain the zinc powder the final solution was cleaned and filtered with bidistilled water for 5 hours to obtain neutral $\mathrm{pH}$ and then dried.

\section{Morphology and Structure Characterization}

\subsection{SEM Analysis}

Performing Scanning Electron Microscopy (SEM) with an FEI Company microscope, type Inspect $\mathrm{S}$ we analyzed the structure of $\mathrm{Zn}_{0.8} \mathrm{Fe}_{2.2} \mathrm{O}_{4}$ powder and show typical micrographs in Figures 1(a),1(b). For the sample S1 shown in Figure 1(a) syntesized by the coprecipitation method the surface has compacted shapes with round particles, while for sample S2 shown in Figure 1(b) obtained by the hydrothermal method the particles exhibit elongated shapes. For both samples the micrographs exhibit compact structures with smallest particles sizes typically less than $100 \mathrm{~nm}$. Thus we observed structural 

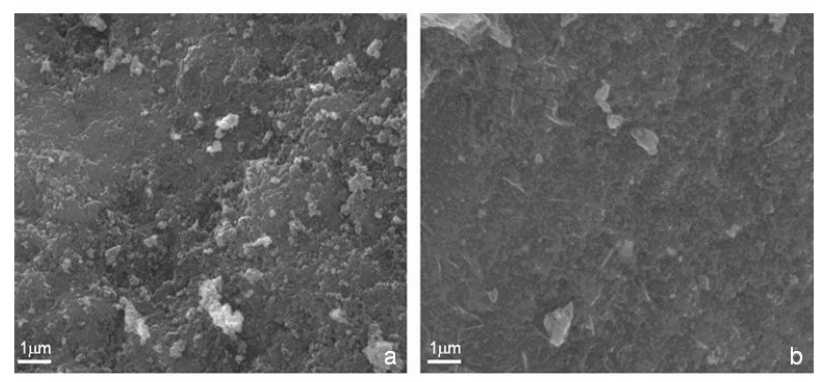

Figure 1. SEM micrographs of $\mathrm{Zn}_{0.8} \mathrm{Fe}_{2.2} \mathrm{O}_{4}$ powders for sample S1-coprecipitation (a) and sample S2-hydrothermal (b).

differences in the aggregation of the material for the two synthesis techniques.

\subsection{XRD Analysis}

Figure 2 shows typical X-ray diffraction patterns of $\mathrm{Zn}_{0.8} \mathrm{Fe}_{2.2} \mathrm{O}_{4}$ powder analysed with a Philips difractometer, type X'Pert PRO MPD.

The measurements were done in the $2 \theta$ range of $20^{\circ}$ $90^{\circ}$ for samples of zinc ferrites obtained by the two techniques. The calculated distance between the main crystal planes was $0.2 \mathrm{~nm}$. Well defined diffraction peaks corresponding to the characteristic planes (311), (511) and (440) apear at $35^{\circ}, 57^{\circ}$ and $64^{\circ}$. The intensity of the peaks reveal that the sample S2 obtained by the hydrothemal method has bigger particles then the sample S1 obtained by coprecipitation. Other wide diffraction peaks corresponding to (220), (442), (553) and (731) planes are also present with low relative intensities asumed to arise from an amorphous structure. Using the Scherrer Equation [14] the measured size of zinc ferrites particles was bellow $100 \mathrm{~nm}$.

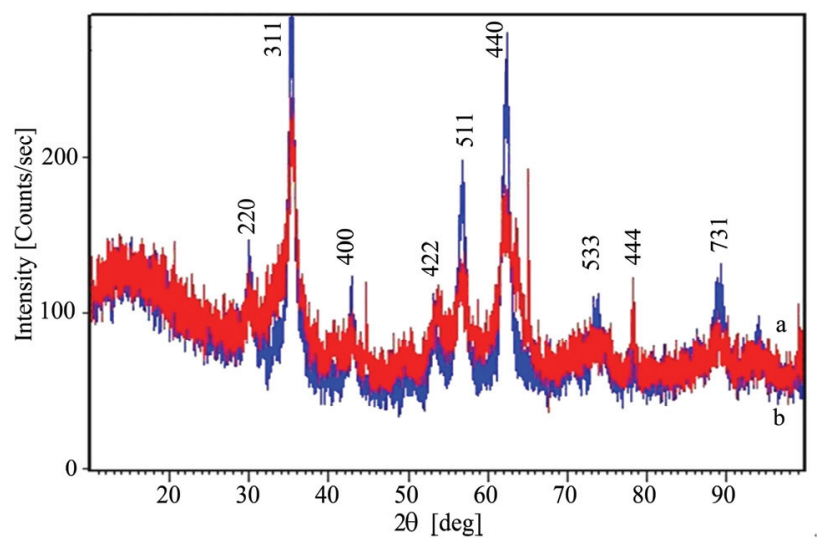

Figure 2. XRD graphs of $\mathrm{Zn}_{0.8} \mathrm{Fe}_{2.2} \mathrm{O}_{4}$ obtained by two synthesis methods for sample $\theta \mathrm{S} 1$-coprecipitation (a) and sample S2-hydrothermal (b).

\section{Magnetic Hysteresis Measurements}

We analyzed the magnetic behavior of the zinc ferrite obtained by coprecipitation and hydrothermal methods by measuring the magnetization as a function of an applied $50 \mathrm{~Hz}$, AC magnetic field amplitude up to 160 $\mathrm{kA} / \mathrm{m}[15]$.

In Figures 3(a),3(b) the M-H curves of the sample $\mathrm{S} 1$ and $\mathrm{S} 2$ obtained by the two synthesis methods are given.

In the case of the sample S1 obtained by coprecipitation a superparamagnetic-like behavior was observed, with a maximum magnetization of $200 \mathrm{~A} / \mathrm{m}$ at $160 \mathrm{kA} / \mathrm{m}$. The maximum magnetization of the sample $\mathrm{S} 2$ obtained by the hydrothermal method is $750 \mathrm{~A} / \mathrm{m}$ for a maximum applied field of $160 \mathrm{kA} / \mathrm{m}$, the magnetic remanence was $70 \mathrm{~A} / \mathrm{m}$ and coercivity about $6.40 \mathrm{kA} / \mathrm{m}$.

\section{Discussion}

The analysis of the morphology and structure by electron microscopy for zinc ferrites shows that the powders are composed of particles with diameters bellow $100 \mathrm{~nm}$ for both S1 - coprecipitation and S2-hydrothermal samples. From the x-ray diffraction measurements we observe for both synthesis methods the crystal planes (311), (511)

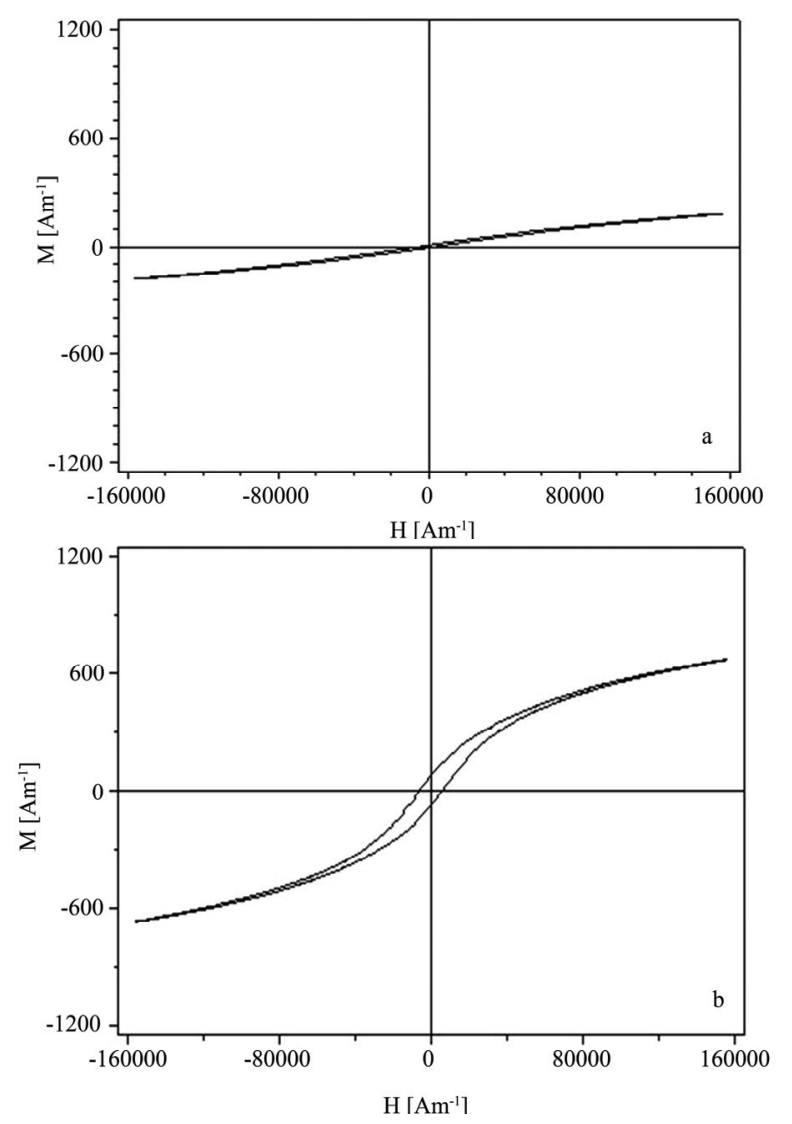

Figure 3. Hysteresis curves of the $\mathrm{Zn}_{0.8} \mathrm{Fe}_{2.2} \mathrm{O}_{4}$ powders for sample S1-coprecipitation (a) and S2-hydrothermal (b). 
and (440) though the intensity of the peaks of the zinc ferrite obtained by the hydrothermal method gave bigger particles by about $10 \%$ as compared to the coprecipitation method. These diffraction peaks correspond to the main diffraction planes in zinc ferrites although some amorphous material structure is observed also by the wide and small peaks of planes (220), (442), (553) and (731). We also observed that the structure for the sample S2-hydrothermal is more crystalline while for the sample S1-coprecipitation the surface structure is more homogenous.

From the hysteresis measurements the $\mathrm{Zn}_{0.8} \mathrm{Fe}_{2.2} \mathrm{O}_{4}$ powders obtained in this investigation we obtained a ferromagnetic behavior [16] with stronger hysteresis for the sample S2-hydrothermal wich means that they can be stronger magnetized.

\section{Conclusions}

Two synthesis methods were investigated to obtain the zinc ferrites with magnetic properties usable for shielding applications.

The zinc ferrite nanopowder synthesized by the hydrothermal technique shows a higher magnetic behavior as seen from the hysteresis curves. From x-ray diffraction measurements the zinc ferrite particles for sample S2hydrothermal have bigger sizes compared to the samples S1 - coprecipitation. The ferrite nanopowder obtained by both methods show small particles with diameters typically bellow $100 \mathrm{~nm}$ resting on a more planar structure.

We conclude that the synthesis method has important influence on the morphology, structure and magnetic behavior of the zinc ferrite nanopowders and in our case the hydrothermal method gave superior magnetic results.

\section{REFERENCES}

[1] H. Montiel, G. Alvarez, M. P. Gutiérrez, R. Zamorano and R. Valenzuela, "Microwave Absorption in $\mathrm{Ni}-\mathrm{Zn}$ Ferrites through the Curie Transition," Journal of Alloys and Compound, Vol. 369, 2004, pp. 141-143.

[2] H. W. Wang and S. C. Kung, "Crystallization of Nanosized Ni-Zn Ferrite Powders Prepared by Hydrothermal Method," Journal of Magnetism and Magnetic Materials, Vol. 270, 2004, pp. 230-236.

[3] A. M. Kumar, M. C. Varma, C. L. Dube, K. H. Rao and S. C. Kashyap, "Development of Ni-Zn Nanoferrite Core Material with Improved Saturation Magnetization and DC Resistivity," Journal of Magnetism and Magnetic Materials, Vol. 320, 2008, pp. 1995-2000.
[4] Y. Hwang, "Microwave Absorbing Properties of NiZnFerrite Synthesized from Waste Iron Oxide Catalyst," $M a-$ terials Letters, Vol. 60, 2006, pp. 3277-3280.

[5] M. Wen, Q. Li and Y. Li, "Magnetic, Electronic and Structural Properties of $\mathrm{Zn}_{x} \mathrm{Fe}_{3-x} \mathrm{O}_{4}$," Journal of Electron Spectroscopy and Related Phenomena, Vol. 153, 2006, pp. 6570.

[6] M. Koledintseva, J. Drewniak, Y. Zhang, J. Lenn and M. Thoms, "Modeling of Ferrite-Based Materials for Shielding Enclosures," Journal of Magnetism and Magnetic Materials, Vol. 321, 2009, pp. 730-733.

[7] M. Sivakumar, A. Towata, K. Yasui, T. Tuziuti and Y. Iida, "A New Ultrasonic Cavitation Approach for the Synthesis of Zinc Ferrite Nanocrystals," Current Applied Physics, Vol. 6, 2006, pp. 591-593.

[8] A. D. Sheikh and V. L. Mathe, "Anomalous Electrical Properties of Nanocrystalline Ni-Zn Ferrite," Journal of Material Science, Vol. 43, 2008, pp. 2018-2025.

[9] K. Kondo, T. Chiba, H. Ono, S. Yoshida, Y. Shimada, N. Matsushita and M. Abe, "Conducted Noise Suppression Up to GHz Range by Spin-Sprayed $\mathrm{Ni}_{0.2} \mathrm{Zn}_{\mathrm{x}} \mathrm{Fe}_{2.8-\mathrm{x}} \mathrm{O}_{4}$ ( $\mathrm{x}=$ 0.3, 0.6) Films Having Different Natural Resonance Frequencies," Journal of Magnetism and Magnetic Materials, Vol. 301, 2006, pp. 107-111.

[10] A. C. F. M. Costa, E. Tortella, M. R. Morelli, M. Kaufman and R. H. G. A. Kiminami, "Effect of Heating Conditions during Combustion Synthesis on the Characteristics of $\mathrm{Ni}_{0.5} \mathrm{Zn}_{0.5} \mathrm{Fe}_{2} \mathrm{O}_{4}$ Nanopowders," Journal of $\mathrm{Ma}$ terial Science, Vol. 37, 2002, pp. 3569-3572.

[11] L. Chen, Y. Shen and J. Bai, "Large-Scale Synthesis of Uniform Spinel Ferrite Nanoparticles from Hydrothermal Decomposition of Trinuclear Heterometallic Oxo-Centered Acetate Clusters," Materials Letters, Vol. 63, 2009, pp. 1099-1101.

[12] A. Rafferty, Y. Gunko and R. Raghavendra, "An Investigation of Co-Fired Varistor-NiZn Ferrite Multilayers," Materials Research Bulletin, Vol. 44, 2009, pp. 747-752.

[13] W. Yan, Q. Li, H. Zhong and Z. Zhong, "Characterization and Low-Temperature Sintering of $\mathrm{Ni}_{0.5} \mathrm{Zn}_{0.5} \mathrm{Fe}_{2} \mathrm{O}_{4}$ NanoPowders Prepared by Rrefluxing Method," Powder Technology, Vol. 192, 2009, pp. 23-26.

[14] R. Jenkins and R. L. Snyder, "Introduction to X-ray Powder Diffractometry," John Wiley and Sons Inc., New York, 1996.

[15] I. Mihalca, A. Ercuta and C. Ionascu, "The Villari Effect in $\mathrm{Fe}-\mathrm{Cr}-\mathrm{B}$ Amorphous Ribbons," Sensors and Actuators $A$, Vol. 106, 2003, pp. 61-64.

[16] N. Spaldin, "Magnetic Materials: Fundamentals and Device Applications," Cambridge University Press, United Kingdom, 2003. 